anomalies were significantly higher in mothers $<20$ years $(201$ per 10,000 [95\% CI: 164 to 245]) compared to the mean for all ages (147 per 10,000 [95\% CI: 141 to 154]). The birth prevalence of Edwards' syndrome increased on average by 1.2\% (95\% CI: $0.2 \%$ to $2.3 \%$ ) per year between 2005 and 2014.

Conclusion The development of an effective national CA registration system has proved feasible, and reporting for the whole of England should be possible from the 2017 birth cohort onwards. Accurate national surveillance and monitoring of congenital anomalies and rare diseases is set to become a powerful tool to address child morbidity and mortality.

\section{CONGENITAL TOXOPLASMOSIS - SURVEILLANCE AS KEY TO INFORM THE NATIONAL PREVENTION POLICY SWITZERLAND AS A TYPICAL EXAMPLE OF A LOW INCIDENCE COUNTRY}

C Rudin. Universitäts-Kinderspital beider Basel, Switzerland

\subsection{6/archdischild-2018-rcpch.487}

Background The results of a first national survey of symptomatic congenital toxoplasmosis using the Swiss Paediatric Surveillance Unit (SPSU) and data from two regional cord blood screening programs in western and northwestern Switzerland led to a change of paradigm in Switzerland in 2008, abandoning widespread non-systematic toxoplasmosis screening during pregnancy in our country.

Aim A second identical survey of symptomatic congenital toxoplasmosis was started in 2009 following abolition of toxoplasmosis screening during pregnancy with the aim to exclude any adverse impact of this change in paradigm on the incidence of congenital toxoplasmosis.

Results During the first survey period of 4 years between 1995 and 199815 proven cases of symptomatic congenital toxoplasmosis were reported, corresponding to 4 cases per year or an incidence of 1.36 per $100^{\prime} 000$ children of age $0-$ 15 in Switzerland. This exactly corresponded to our expectation calculated for Switzerland based on results of two cordblood screening programs in western parts of Switzerland (Basel and Lausanne), expecting at most 130 primary toxoplasmoses among 73'000 pregnant women, with 32 cases of congenital toxoplasmosis of which 4.5 were expected to be symptomatic each year.

During the second eight years' survey period between 2009 and 2017 only five children with symptomatic congenital toxoplasmosis were reported, which corresponds to less than one case per 100'000 children of age 0-15 in Switzerland.

Conclusion Despite abolishment of wide-spread non-systematic screening in 2008, incidence of congenital toxoplasmosis has continued to steadily decrease in Switzerland. Our data support abandoning toxoplasmosis screening programs in low-incidence countries such as Switzerland.

\section{INFLUENCING THE NATIONAL DEBATE ON MEDICAL ASSISTANCE IN DYING (MAID): LEVERAGING THE CANADIAN PAEDIATRIC SURVEILLANCE SYSTEM (CPSP) TO INFORM THE POSITION OF THE CANADIAN PAEDIATRIC SOCIETY (CPS)}

C Moore-Hepburn. Department of Paediatrics, University of Toronto, Toronto, Canada

\subsection{6/archdischild-2018-rcpch.488}

Aims In June 2016, Bill C-14 was enacted in the Canadian Parliament, allowing medical assistance in dying (MAID) for consenting adults with 'grievous and irremediable medical conditions' experiencing 'intolerable' suffering whose deaths are 'reasonably foreseeable'. Minor patients (both mature and 'never competent' minors) are currently excluded from the legislation. An independent review of the issue of minor patients and MAID was requested by Parliament.

As health professionals, politicians and the public grappled with this issue, never before formally contemplated in Canada, the Canadian Paediatric Surveillance Program (CPSP) sough to provide data on exploratory conversations and explicit requests for MAID from/for minor patients to inform the independent review.

Methods The CPSP is a joint program of the Public Health Agency of Canada and the Canadian Paediatric Society. The program conducts national surveillance into diseases that are high in disability, morbidity and economic costs to society, despite their low frequency. The CPSP surveys over 2500 paediatricians and paediatric subspecialists each month to monitor rare diseases, conditions and complications in Canadian children.

A one-time survey was sent to all CPSP participants in May 2016. The survey tool can be accessed at www.cpsp.cps.ca/ surveillance.

Results The survey response rate was $40 \%$. Over one-third of participants reported they provide end-of-life or palliative care (370;35\%).

Exploratory discussions with minor patients about MAID were reported by 35 participants, representing 60 patients, the majority of whom were 14-18 years of age. Nine (9) participants recalled an explicit request for MAID, representing 17 minors.

Exploratory discussions with patients about MAID, on behalf of minor patients, were reported by 118 participants, representing 419 minor patients, the majority of whom were under 1 year of age. Forty-five (45) participants recalled an explicit request for MAID, representing 91 parents, the majority of whom had children under 1 year.

Conclusion CPSP participants from across Canada reported exploratory conversations about and explicit requests for MAID from both minors and parents. Discussion with and explicit requests from parents outnumber those by minors by more than five to one.

This study represents an important and innovative use of a paediatric surveillance system to inform a national conversation on a complex emerging ethical issue. 